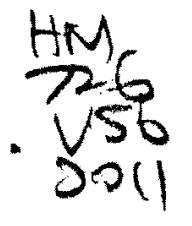

\title{
PERCEPTIONS ON INTERGENERATIONAL SOLIDARITY AMONG FILIPINO IMMIGRANT YOUTH IN THE GREATER TORONTO AREA
}

by

\author{
Helena Viola, BA Honours, University of Toronto, 2010 \\ A Major Research Paper \\ presented to Ryerson University
}

in partial fulfillment of the requirements for the degree of

Master of Arts in the Program of

Immigration and Settlement Studies

Toronto, Ontario, Canada, 2011

(C) Helena Viola 2011 


\section{Author's Declaration}

I hereby declare that I am the sole author of this major research paper.

I authorize Ryerson University to lend this paper to other institutions or individuals for the purpose of scholarly research.

I further authorize Ryerson University to reproduce this paper by photocopying or by other means, in total or in part, at the request of other institutions or individuals for the purpose of scholarly research.

Signature

Signature 


\title{
PERCEPTIONS ON INTERGENERATIONAL SOLIDARITY AMONG FILIPINO IMMIGRANT YOUTH IN THE GREATER TORONTO AREA
}

Helena Viola, Master of Arts, 2011 Immigration and Settlement Studies

Ryerson University

\begin{abstract}
Young-adult and parent relationships are widely examined throughout the literature. However, there has been very little focus on youths' perspective on the relationships with their parents and families. While, there is a combination of both conflict and solidarity in immigrant families, in my work, I will be looking at the intergenerational solidarity between youth and their parents, from the perspective of young people. This study is exploratory and qualitative, and aims to contribute to the research on immigrant Filipino families in the Canadian context. This study found positive views by the youth about their relationship with their parents. Parental expectations and obligations in family matters, such as school and career aspirations were deemed important by the youth participants. Despite some disagreements on issues, such as dating and career choices, the youth reported agreement with their parents on family values such as respect and obligation to the family.
\end{abstract}

Key words: Filipino, Intergenerational Solidarity, Youth, Immigrant 


\section{Acknowledgements}

To God, mom, dad, and brother. My pamilya.

Many thanks and appreciation to my MRP supervisor, Dr. Vappu Tyyskä. I couldn't have done this without your tremendous helpful advice, guidance, and amazing support throughout this journey!

I acknowledge my second reader, Dr. Mehrunnisa Ali for her helpful comments and suggestions for my paper. 
Author's Declaration $\quad$ ii

Study Abstract

Acknowledgements $\quad$ iv

Table of Contents $\quad v-v i$

Chapter

1. INTRODUCTION

1.0 Introduction 1

1.1 Research Design and Research Question 2

1.2 Theoretical Framework 3

1.3 Analytical Framework 4

1.4 Filipinos: an invisible minority 4

1.5 A Brief History: Filipino Imimigration to Canada 5

2. REVIEW OF LITERATURE

2.0 Inclusion and Exclusion Criteria $\quad 8$

2.1 Intergenerational Family Solidarity 10

2.2 Youth-oriented perspective on family relationship 11

2.3 Adolescence and Family Relations 11

2.4 Acculturation and Immigrant Families $\quad 12$

2.5 Individualism and collectivism as family values 14

2.6 Intergenerational/cultural conflict 14

$2.7 \quad$ Filial Responsibility 15

2.8 Filipino Intergenerational Relations 17

2.9 Strong Family Relationships 19

2.10 Summary of literature Review 20

3. RESEARCH METHODS

3.0 Participants $\quad 21$

$\begin{array}{ll}3.1 & \text { Interview structure } \\ 3.2 & 22\end{array}$

$\begin{array}{lll}3.2 & \text { Thematic Coding } & 23\end{array}$

3.3 Limitations to the Study $\quad 24$

4. FINDINGS

4.0 Impact of Immigration on the Family 25

4.1 Functional Solidarity 29

4.2 Normative Solidarity: Family Values [Expectations from Family] 32

$\begin{array}{lll}4.2 .1 & \text { Sense of Freedom } & 35\end{array}$

$\begin{array}{lll}4.3 & \text { Consensual Solidarity } & 37\end{array}$

$\begin{array}{lll}\text { 4.3.1 } & \text { Filipino Values } & 37\end{array}$ 
4.3.2 Filial Responsibility and Expectations $\quad 40$

4.4 Additional Aspects of Intergenerational Relations 42

4.4.1 Relationship with Parents $\quad 42$

$\begin{array}{lll}4.4 .2 & \text { Education } & 43\end{array}$

$\begin{array}{ll}4.4 .3 & \text { Strong Family }\end{array}$

5. CONCLUSION

$\begin{array}{ll}5.0 \text { Discussion } & 47\end{array}$

5.1 Implications and Future Research $\quad 50$

Appendix 1

Participant Interview Questions $\quad 53$

REFERENCES

55 


\section{Chapter 1. INTRODUCTION}

\subsection{Introduction}

Despite being the third largest non-European ethnic group (Lindsay, 2007), there is very little written about the Filipino community in Canada, which remains an understudied ethnic group in the Canadian context. In a culturally diverse country such as Canada, the Philippines has been consistently ranked as one of the top ten source countries of immigration to Canada since early 1970s (Chen, 1999, p. 73). This steady flow makes the Filipino community one of the fastest growing ethnocultural communities in the country.

Immigrant families face many challenges, and issues, pertaining to youngadult and parent relationships (Tyyskä, 2003; Dinh, 2006). However, there has been very little focus on the youth-oriented perspective on the relationships with their parents and families (Tyyskä, 2003). The dynamics that exist within immigrant families can range from intergenerational conflict stemming from differing cultural values, to intergenerational solidarity and sharing of family values. While there is a combination of both conflict and solidarity in immigrant families, it seems that a considerable emphasis in the literature has been toward intergenerational conflict (Phinney et al., 2000). Hence, my approach is a shift from this approach and towards looking at the intergenerational solidarity among child-parent family members (Tyyskä, 2003; Merz et al., 2009). This paper attempts to address this topic by specifically focusing on the perspective of the youth, and specifically examining the intergenerational solidarity that may exist among family members. 


\subsection{Research Design and Questions}

This study seeks to answer the main research questions of :'How do immigrant Filipino youth feel about their relationship with their parents'? How does immigration affect their family relationships? What are some of the factors that strengthen their family ties with one another? What are central Filipino values according to the youths' perspective? How do Filipinos negotiate differing value systems in the context of the family? These questions will help trigger important findings on intergenerational relations of the Filipino family in Toronto.

This topic of study is relevant to the Canadian immigration and settlement experience for two reasons; it contributes to (1) the state of knowledge about the Filipino immigrant community as one of the Asian groups; and (2) the broader understanding of the range of intergenerational expectations among different ethnic and racialized minorities.

This research paper begins with a literature review that covers issues on acculturation, family intergenerational relationships and the family solidarityconflict framework. This literature review is followed by the study's methodological approach and findings from interviews conducted with six Filipino youth residing in Toronto. The study's findings have been themed into the following sections; impact of immigration on family relationships, youth perspectives of family relationship and intergenerational solidarity which includes sub-themes such as functional, normative, and consensual solidarity. The paper ends with an overview of the findings, and implications for future research. 


\subsection{Theoretical Framework}

I would like to examine closely the concept of "intergenerational solidarity" developed by Vern Bengston as the theoretical basis for my paper. Derived from the Exchange Theory, (which looks at the giving and receiving, as well as the imbalance and balance between family generations) (Zohar and Sharlin, 2009, p. 168), this theoretical framework examines multiple facets of familial relations with attention to both conflict and solidarity, and builds on categories of shared and agreed upon elements in family relationships between parents and their children (Mangen et al., 1988; Tyyskä, 2003, p. 318). The intergenerational family solidarity model is revealed in six dimensions of parènt-child interaction: associational, affectual, normative, consensual, functional, and structural, however, I will focus on three for my paper. Firstly, one of the important themes in my research is the question of mutual support in family between teens and parents (Bengston's functional solidarity). This refers to general practical support by parents toward teens and vice versa. A second set of questions has to do with general values and opinions of parents. This is Bengston's consensual solidarity that refers to the kinds of values that are central to both the teens and parents, including areas of agreement and disagreement (this has to do with values such as the importance of family and friends and educational and vocational choices). A third area has to do with expectations of family members from one another (Bengston's normative solidarity], that is, what parents expect from their children and vice versa as family members, and the degrees of freedom seen as appropriate by different family members. 


\subsection{Analytical Framework}

My paper will be emphasizing agency and subjectivity of adolescents. Agency is defined by the ways in which young people act on and contest adult power and control. I follow this type of approach, in contrast to the standard adult-oriented parenting research, because it is important to pay attention to subjectivity, which is seen as the ways in which young people interpret and communicate about their relationships with their parents. As Tyyskä (2001) suggests, "Subjectivity and agency are two sides of the same coin, resulting in a youth-oriented approach that overcomes the confines of structural functionalism and traditional family research and builds our understanding of power, influences and solidarity in teen parent relationships" (p. 318).

To better understand the context of their situation and experiences, the following sections are an introduction to a brief discussion of Filipinos and a historical review of Filipino immigration to Canada.

\subsection{Filipinos - an invisible minority}

It has been proposed that Filipinos are an "invisible minority" or a "minority within a minority" because they are grouped with other Asian ethnic groups such as Chinese, Japanese or Koreans. One of the reasons would be that Filipinos have a different history from other Asian groups; their homeland was colonized by not only the Spaniards but by the Americans. As Hassan (2008) writes, "Formerly colonized by both the Spaniards and the United States, Filipinos are proud of their Asian roots and family cohesion and loyalty are highly valued" (p. 174) 
Consistent with this argument that Filipinos are a "minority within a minority" speaks volumes about how Filipino immigrant youth socialize in mainstream society. In her study of Filipino immigrant youths in Montreal, Li (2006) makes an important reference to the double colonization of the Filipino experience ( 400 years by Spain, 45 years by the USA) that produced lasting psychological and cultural consequences (p. 24). In other words, the self- concept of the Filipinos as "powerless and inferior" was reinforced due to a history of colonialism and exploitation, and as such Filipinos are still defining their cultural, racial and historical identity in the hopes, $\mathrm{Li}(2006)$ writes:“...[t]hat they perceive themselves as their own people, no matter whether other Asians see Filipinos as very westernized, while American and Europeans seem them as very Asian"(p.24). In essence, such sentiments can contribute to how Filipino immigrant youths deal with peer pressure, and how they socialize and interact with the mainstream society.

Highlighting the importance of Filipino history is important in order to contextualize how Filipino immigrant communities in their past have largely influenced their present situation and how their history has shaped the shared understanding and experiences for these Filipino immigrant youth in dealing with immigration and family life in a new country.

\subsection{A Brief History: Filipino immigration to Canada}

Filipino migration to Canada can be divided into three historical periods. It has been noted that the first wave was from 1960s to early 1970 s wherein Filipinos started coming to Canada in significant numbers starting in the late 1960s (Chen, 1997, p. 66). As Chen (1998) points out, beginning in 1962 a significant change in the 
Canadian immigration policy brought a gradual decline of immigration from Europe, and a steady increase of those from the $3^{\text {rd }}$ world, notably from Asia (p. 118). Most who were professionals (such as doctors, nurses, teachers) entering Canada as landed immigrants.

Studies on the adaption and adjustment of Filipino Canadians provide evidence that Filipinos do not seem to have encountered serious difficulties in integrating themselves into the mainstream of Canadian society (Chen, 1997, p. 53). However, this may be an understatement given that before the 1960s, Filipinos and other Asian groups were discouraged from entry by the "head tax", which meant that entry to Canada was heavily restricted and selected. After immigration laws were changed, however, Canada began to welcome Asian, which included a significant increase of Filipino immigrants. In 2001, the Philippines ranked fourth among countries of origin for immigrants to Canada, in 1961 (Corrigan, 2005, p. 55). Corrigan (2005) also indicates that by mid-2002, roughly a quarter of a million Filipino immigrants resided in Canada (p.55).

The second wave of Filipino migration was marked by the flow of professional and skilled workers in the latter part of the 1970s. Highlighting their significant presence in Canada, in 1967, the top four destination provinces for Filipinos were Ontario, Quebec, Alberta and British Columbia, Ontario being the top destination by 1973 with 13, 849 Filipinos (Betsayda, 2008). According to Bustamante (1984), Toronto (and particularly the St. Jamestown area) became the top site to live in for many Filipinos in the late seventies, and continues to thrive today for many newcomer Filipinos. 
And lastly, the third and most recent Filipino migrant cohort is responsible for the substantial family reunification in the 1980 s and onwards, which consist of a mixture of Filipino professionals, skilled and unskilled workers, such as temporary foreign workers (through the Foreign Domestic Movement as well the more recent Live-in Caregiver Program). It is important to note that Filipinos who came to Canada since 1967 have experienced family migration with an increasing number of children and the elderly, in fact, from 1995 to 2004, over 115000 Filipinos became permanent residents in Canada (Caro, 2008; Chen, 1998, p. 11). This increasing number of Filipinos migrating to Canada has resulted to it being one of the ten leading source countries of immigration to Canada (Chen, 1998, p. 13). And as Corrigan (2004) points out, in 2001, the Philippines became the fourth largest immigrant population in Canada. 


\section{Chapter 2. REVIEW OF LITERATURE}

This section reviews the scholarship on youth-parent relations and the experiences of youths in their relationships with their parents. Given that the major theme in the research study is focused on intergenerational solidarity held by Filipino families, previous literature provides the backdrop to the exploration of the examination of various themes, such as: intergenerational solidarity, acculturation, filial responsibility, and conflicting value systems that may either weaken or strengthen family relationships.

The studies included in this paper were identified from the psychological, sociological, gerontological and medical literature through the electronic databases Web of Science (Social Sciences and Arts and Humanities citation indices), PubMed, PsychiNFO, Sociological Abstracts, Academic Premier Search, Proquest, SAGE Journals Online, Wiley, Scholars Portal in the time period of early 1990s to 2010 , using the following key terms or descriptors: intergenerational support, coping behavior, family conflict, parent-child relations and relationship quality, international solidarity, adult children, Filipino families AND relationships, Asian youth, immigrant families, Asian immigrants, Filipino immigrants, Filipino youth. Furthermore, the reference lists of the retrieved articles were checked for relevant studies. Specific Journals by Title included Journal of Early Adolescence, Journal of Family Psychology, Journal of Family Issues Journal of Cross Cultural Gerontology, Journal of Cultural Ethnic Studies and Journal of Canadian Ethnic Studies.

\subsection{Inclusion and exclusion criteria}


The following criteria were used to decide whether studies could be included in the present analysis: First, all studies had to report associations between conflicts/tensions or solidarity (closeness of family ties) in adult child-parent relationships. Second, I limited the criteria to immigrant families in order to garner a better understanding of youth-parent relationships and the issues that may arise within the context of immigration. Studies examining the problems of acculturation and adaptation were included because it related to my theme of immigration experiences of racialized groups and issues involving education and family matters. Studies that looked at the health problems or mental health issues of children of immigrant parents, or newcomers were largely excluded, because this type of information was more oriented toward physical and mental health issues and would not be comparable with issues on family relationships in other studies. In addition, the studies had to describe an emphasis on family relationships between parent and child (youth/young adult) that pertained to issues around intergenerational conflicts/tensions, or specific issues, such as academic achievement, cultural differences and tensions around issues of dating, and gender roles. There were several studies looking at child development and acculturation within Asian American families (primarily Chinese immigrant families) and the context of family obligations (filial responsibilities) and cultural tensions (Hyman and Beiser, 2006; Yoshikawa and Way, 2008; Xiong et al, 2005; Dinh and Nguyen 2006; Merz et al 2009; Ying et al., 2001). To date, there are relatively few studies that have looked into Filipino young adults and their perceptions of their relationships with their 
parents. However, the themes uncovered in other immigrant families have strong similarities, suggesting that we may find these patters in Filipino families as well.

I included studies published in English in American, Australian and Canadian contexts, to address the low number of studies on specifically Filipino immigrant families. Finally, to establish a minimum study quality, the majority of studies published in scientific, peer-reviewed journals were included in the analysis, with the addition of book chapters, and short articles or reports from CERIS - The Ontario Metropolis Centre.

\subsection{Intergenerational Family Solidarity}

As mentioned previously in my theoretical framework section, the concept of "intergenerational solidarity" developed by American researcher Vern Bengston in the 1970 s builds on categories of shared and agreed upon elements in family relationships between parents and their children" (Tyyskä, 2003, p. 318). Although some scholars (Conndis and Mullen 2008 cited in Lowenstein, 2007, p. S101) have criticized the theory as being unidimensional and that it paints an incomplete picture of intergenerational relationships as being only positive, the solidarity model has been adapted over the years to be multidimensional in that it considers both conflict and solidarity (the family solidarity-conflict model) within a life course for both the parent and child (Lowenstein, 2007; Bengston and Roberts, 1991). The term "solidarity" represents the complex relationships between parent and child, that includes the close examination of behaviors, sentiments, and attitudes within family relationships (Lowenstein, 2007, p. S100; Hebblethwaite, 2008, p.19). Furthermore, Bengston and colleagues developed six categories of family solidarity 
(affectual, associational, consensual, functional, normative and structural)

(Bengston, 1991, 2006), however, I focus on three (functional, normative and consensual) for my paper because these three chosen principles help capture what I intend to look for in understanding the experiences and perspectives of the youth towards their parents such as, speaking about issues on differing value-systems (consensual), supportive systems (functional), and the expectations from family members, such as filial obligations (normative).

\subsection{Youth-oriented perspective on family relationship}

Although there are studies based on children's subjective perceptions of their parents' acculturation (Costigan and Dokis, 2006), the literatures on immigrant youths' perspective on their relationship with their immigrant parents have remain sparse. Most recent studies focus on children or young adults' perception on their roles of a 'caregiver' to their aging parents or to their grandparents are in relation to the concept of "filial responsibility", that is, of taking care of their elderly loved ones (as commonly seen in Asian families; see Wong 2001; Yoshikawa 2008; Merz, Schulze; and Schuengel 2009; Vedder, 2009; Bales, 2002; Monserud, 2008).

\subsection{Adolescence and Family Relations}

Adolescence is the transition period from childhood to adulthood. This is a time when society ceases to regard this period as a child but does not yet accord them a full adult status (Medina 1991, p. 202). Adolescents (or young adults) are in that transitional phase of reaching adulthood, thereby disagreements and conflicts, with parents are considered a normal part of the process of asserting autonomy and developing independence (Stuart et al 2010, p.116). This can be linked to the notion 
of developmental stake, in which young adolescents may need to perceive greater differences in family values and attitudes among family members, in order to develop one's identity (Weiner et al., 2003, p. 493; Tyyskä, 2003). This means that adolescents' perceptions of their relationship with their parents may change, including perceptions of solidarity. However, intergenerational conflicts may also affect this developmental shift for immigrant youths in the context of acculturation (Xiong et al 2005, p.160) as they may reject the values of their parents and begin to adopt the dominant culture's values and modes of behavior.

On the other hand, some scholars suggest that although intergenerational conflict is heightened between teen and parent, it has been noted that when a person reaches adulthood (Scalibini et al., 2006), the level of intergenerational conflict around the issues mentioned above diminishes, as a bicultural identity develops and is embraced, and solidarity amongst family members emerges (Pundir 2009:63; Stuart et al., 2010). As pointed out by Baker and Dryden (1993, p.209) it is only later that young people are able to realize that perhaps they and their parents have more in common than they previously believed. This perspective seems to reign true for the youth in my study where a few indicated that they realized and accepted the shared common and interests (via leisurely activities, such as attending parties, going out to the movies] that their parents and themselves had enjoyed with each another.

\subsection{Acculturation and immigrant families}

Families in multicultural societies confront unique challenges (Anisef and Kilbride, 2001, p.8) and for immigrant families, those challenges are often associated with the 
stresses of the acculturation experience that affect the parent-child relationship. Moreover, how immigrant families experience migration is dependent upon several factors, such as the context of host country, immigrants' access to resources, and also the length of residence in the new country.

The "acculturation thesis" which sees a natural progression in which each successive generation adopts more of the "behaviors, rules, values, and norms of the host society" (Tyyska, 2001, p. 138) has been widely used in much interdisciplinary research, such as psychology, health and sociology. As Khabagnote (2003) notes, acculturation can be viewed as being unidirectional process of assimilation(which as mentioned above, entails that an individual adopts the norms, values of the host society) or bidirectional (in which an individual adopts the values, and norms of the mainstream society but still retains their culture of origin's practices, beliefs etc.) ( $p$. 21-2).

However, while acculturation can be viewed into different processes of assimilation, it is important to point out that the experience of acculturation is different amongst every individual and thus, not identical (Khabagnote, 2003). Scholars such as Costigan and Dokis (2006) and Stuart et al., (2010) further assert that varying acculturation rates are associated with an 'acculturation gap'. For example, when dissimilar levels of acculturation exist, children generally acculturate more quickly than their parents, while parents retain their ethnic traditions, which are different from their children's experiences in the receiving country (Costigan and Dokis, 2006, p.1252). This can be linked with acculturative stress, in which feelings of anxiety and depression, etc., during the acculturation process can be 
highly dependent upon the degree of dissimilarities between two cultures, which can be felt differently among family members. In addition, given young immigrant youth are exposed to social institutions more so than their immigrant parents (attending school, interacting with peers, etc.), there is a higher likelihood that there will be family conflict (Dinh and Nguyen, 2006, p.411).

\subsection{Individualism and collectivism as family values}

Asian collectivism is characterized by family cohesion, family obligation and communal reciprocity, in which conforming to these values is highly valued and deemed very important to the Asian culture. As Xiong et al, (2005) asserts, following such norms of obedience and conformity are typically judged as "good" behavior by Asian parents and often children must submit to authority without question.

In relation to Filipino families, the Filipino term "kapwa" is used in reference to the collectivism and unified sense of self with others that Filipinos have within their culture, and is what scholars such as Stirling et al.,(2001) suggest a fundamental difficulty that immigrant Filipinos face in "highly individualistic and industrial societies" (p.297). In her work on Filipino immigrant parents and their daughters in the U.S., Yen Le Espiritu (2001) reports that the respondents constructed their "ethnic" culture as principles (having close knit families )in contrast to the "American" culture as deviant (lacking strong family ties) (p.421). In such cases, most immigrant families often struggle to reconcile these two differing value-systems.

\subsection{Intergenerational/cultural Conflict}

Closely linked to the previous discussion on collectivism and cultural beliefs, is the notion of intergenerational conflict, in which conflict usually arises when the 
behavioral standards and values of two cultures are inconsistent with each other but both demand a sense of conformity to their norms (Wu and Chao 2005, p.516). It becomes more salient and problematic for immigrant families, in particular for Asian families because as mentioned before, they often abide by traditional Asian values such as collectivism, conformity self-restraint and silence (p.4), while adolescents conform to more North American values, such as individualism, autonomy assertiveness, etc., leading to conflicts within families. In his study of Filipinos in Newfoundland, Magasino (1986), cites conflict in differing valuesystems affected parent-child relationships, including typical issues around dating, lack of respect and too much freedoms (cited in Chen, 1990, p.89).

Yau and Semtana (1993) echo this in their study of cultural conflict between Chinese American adolescents and their parents, indicating that "Asian American youth deal with two important process: they must face the challenge of going through normal developmental process that all children have to face and also the process of adapting to the receiving society" (cited in Lee, 2004, p. 4-5).

\subsection{Filial Responsibility}

Addressing the expectations held by parents and their children can be linked to this concept of family obligation and filial responsibility. Fuligni and Pederson (2002) define family obligation as:"...[t]he extent to which family members feel a sense of duty to assist one another and to take into account the needs and wishes of the family when making decisions" (p. 856).

This definition of family obligation seems to follow the notion of filial responsibility because it places a strong emphasis on family duty to support, and 
respect for cultural family traditions. As pointed out in their study of 1,050 high school students in the San Francisco Bay area, Fuligini and Pederson [2002) found that even though Filipino and Latin American young adults had lived in an American society that is characterized by autonomy and independence, they still manage to retain their families' traditional emphasis on assistance and respect to parents and siblings (p. 864). Hence, family obligation can be strong in particular ethnic groups due to their respective cultural family traditions. Within Asian families, this link between Asian heritage and family obligation, duty and loyalty is highly regarded and has been widely documented (Xiong et al. 2005, p.170; Zhou 2009).

Although there is very little literature of Filipino families in the Canadian context, Cimmarusti (1996) gives insight that for Filipino families; duty and a sense of obligation are also very strong (p. 210). The Filipino family is comprised of a complex structure of loyalty, obligation and interdependence (Caliboso, 1998: 21) and these values override individualism. Thus, displays of anger or rebellion are often discouraged, while passive and cooperative behaviors are encouraged (Caliboso 1998, p.21). According to Caliboso, (1998) relationships are maintained primarily through four means: utang ng loob (reciprocal obligation, hiya (shame) amor proprio (self esteem) and pakikisama (getting along with) (p. 21-2). These principles reign high for most Filipino families and parents uphold such values to their offspring.

Similar to the Chinese perspective of maintaining family honor, of upholding important values such as education, Filipinos use this term "hiya" (which literally means shame, or embarrassment) to describe how Filipino families emphasize and 
maintain family and personal honor in their family structure. As Caliboso (1998) asserts, "Hiya is tied to conformity and serves to maintain the importance of the group over the individual" (p. 23). According to Khabagnote (2003) hiya is a sense of conformity towards upholding the group over the individual, in this case, the group is the family who carries and maintains the values and morals within the family.

\subsection{Filipino Intergenerational Relations}

As discussed above, the most important aspect of Filipino culture is the family. Consistent with the previous section on filial responsibility, the importance of family solidarity is highly valued for it places certain obligations that is expected on family members, such as the their loyalty and dependence on one another (Khabagnote 2003).

The Filipino family can be seen as a prototype of what has been in the Philippines (Aranas 1983, p.104). For instance, Medina (2001) describes childrearing practices in the Philippines as being "nuturant, affectionate, indulgent and supportive" (p.226). As Medina (2001) indicates, parents tend to be both overprotective, and at the same time disciplinarian to their children. This approach to parenting can be applied to the context of Filipino families migrating and living in a foreign society as they raise their children. Such practices can affect and influence the type of relationship they wish to have with their offspring, which can play a major role in how the children of these immigrant parents perceive their parents. For example, in her study of second-generation Filipino youths in California, Wolf (1997) describes the respondents ' relationship with their parents, as, "suffering in 
silence", in that they had difficulty in confiding to their parents for emotional support, because of conflicting emotions (as these youths did have strong family values) but yet experienced frustrating lines of communication (not sharing inner feelings with parents for fear of disappointment) (p.471).

Gender expectations for Filipinos living in the America seem to be similar in many ways to patterns in the Philippines, given that boys generally enjoy more freedoms (such as going out late) while girls are restricted and over protected by their parents (mostly for fear of unwanted pregnancies). This is reinforced by Filipina American scholar Yen Espiritu, (2001) who indicates that the process of parenting is gendered in that immigrant parents tend to restrict the autonomy, mobility and personal decision making of their daughters more than that of their sons (p. 431).

Moreover, it is often the daughter who has the primary burden of protecting and preserving the family (Espiritu 2001, p.428). Espiritu (2001) writes, "Because sons do not have to conform to the image of an ideal ethnic subject as daughters do(that being, seen as nurturing, modest and conservative), male sons often enjoy special day-to-day privileges denied to daughters" (p. 429). This is not to say that immigrant parents do not place any expectations on their sons; rather, expectations are not focused around the sons' sexuality or dating choices, but more on getting a job and contributing to the family's income. In contrast, as Espirtu [2001] notes, "parental control over the movement and action of daughters begins the moment they are perceived as young adults and as sexually vulnerable" (p.429). 
This is consistent with Tyyskä's findings (2005) wherein she points out that adolescent girls in some immigrant families have much less freedom of movement and decision making power than their brothers (also see Anisef, 2001). This freedom can range from dating, drinking, interacting with friends, late nights, and working while in school (Pundir 2009, p.44; Espiritu 2001).

\subsection{Strong Family Relationships}

The research on the linkage between the family as a form of social support and the process of adaptation can be linked to the positive outcomes on intergenerational solidarity that exists within families. Recent research provides evidence of much strength within immigrant families in the acculturation process (Pundir, 2009, p.8;

Stuart et al., 2010). As Pundir (2009) points out, what has frequently been ignored is the capacity of families to successfully adapt and adjust in the two cultural worlds of ethnic and mainstream society (p.72). Scholars such as Stuart and colleagues (2010) agree with this, arguing that the" family can play an important role in fostering the psychological well being of its members in providing social support, transmitting cultural values and nurturing a sense of belonging" (p.115). This collective sense of family support is confirmed by Herrera's essay on Filipino families in America [1997], where she indicates that Filipino families have high levels of sharing, with respect to time and money (p.16). Often sharing could be from spending time with one another, or the pooling of financial resources to help clear expenses such as helping family members attend college/university, or to help relatives back home in the Philippines. By having family members collectively help each other, families can 
act as a buffer amidst the negative impacts of immigration and acculturation (Stuart et al., 2010, p. 116).

\subsection{SUMMARY OF LITERATURE REVIEW}

The general consensus within the literature is that immigrant families undergo a process of change and transformation as they are faced with new norms that may affect their family relationships (i.e., differing value systems, socioeconomic mobility). However, it is important to consider that families are always in a constant state of change. In the process of acculturation, family relations can manifest a combination of both solidarity and conflict depending on family dynamics and situations (Cruz-Saco and Zelenev, 2000, p.61).

For most Asian families, in particular Filipino families, family is a central aspect to their culture. Intergenerational solidarity is maintained by ensuring that one's cultural values, such as filial responsibility and duty towards ones family override the individual's self interests. In fact, as Khabagnote (2003) notes, loyalty and dependence on family members is the principal concern for Filipino families (p.18). Moreover, as the literature indicates, family relationships tend to hold together despite the challenges faced by acculturation and immigration, and this is indicative of intergenerational solidarity. 


\section{Chapter 3. RESEARCH METHODS}

First, it is important to consider that my positionality, which refers to an individual's relation to the other (Zerat, 2009) can be a seen as strength to this study, given that as a young Filipina adult, raised by immigrant parents, I can say that I do share some similarities with the participants. Thus, as an insider I can also be seen as a representative of these participants. It is possible that it helped in the process of recruitment and enabled the participants to respond to my research in a helpful way. However, I made every effort to avoid carrying any assumptions about my experiences and subjective perceptions, to their relationships with their parents.

The methodology I used for my research study is qualitative research. Qualitative research analyzes data, by connecting particular data to concepts and identifying broad themes. I conducted semi-structured interviews (Neuman, 2011, p. 507). This allowed for in-depth knowledge for the purpose of assessing Filipino youths' attitudes about their relationships with their parents. General questions were asked about: family settlement and adjustment to life in Canada, the youth's overall relationship with her/his parents, and differences in the youth's relationships with her/his mother and father. The interview consisted of three content areas of intergenerational solidarity: functional solidarity, normative solidarity and consensual solidarity.

\subsection{Participants}

The present study relied on individual interviews with youth aged 16-21 from the Toronto Filipino community. I chose this particular age group because based on the literature review above; this is a critical time period when youths are gradually 
beginning to transition from adolescence to adulthood. Understanding their thought processes, feelings and opinions about their relationships with their family members, especially their parents, and how they view themselves these relationships, well help shed light to the experiences of Filipino youths in that matter. Participants were selected on the basis of gender and age in order to have a diverse set of participants in the study, although the sample itself is not scientific (non-representative/non-probability). The participants in this project consisted of six Filipino youths who were recent immigrants to Canada (within the last four to six years) or had recently obtained Canadian citizenship. All participants were either high school or university/college students. Three males and three females were interviewed for the study.

The participants were recruited using the snowball-sampling method (Neuman, 2011). As a Filipina, I initially used my network of acquaintances to recruit Filipino youths. Each participant youth was then requested to refer additional people who might be interested in the study. Participants were informed about the voluntary nature of the study and the confidentiality procedures in the research, based on the Research Ethics procedure.

\subsection{Interview structure}

The interviews took place in mutually agreed upon locations in mid July 2011 . The interviews were digitally recorded and transcribed. At the beginning of the interview, an attempt was made to develop rapport with the participants by asking them a bit about their family background. In addition, an attempt was made to keep the interview conversational and informal. The participants were reminded that the 
questions posed were in an open format and if they wished to share something additional at any point, they were free to do so. Many times, additional probes to clarify or explore the experiences shared by participants followed the initial question. The style of interviewing was facilitative allowing the participants to share whatever they wanted while being respectful of the emotional and deeply personal nature of the experiences being shared by them (Neuman, 2011).

At the time of the interview the participants were asked if they had any questions or concerns before they signed the consent form. Only after the consent forms had been signed were the interviews conducted. The interview questions were open-ended (see Appendix I). Also, the interviews were audio-recorded using a high quality digital recorder. All the names of the participants were changed in order to maintain anonymity and confidentiality.

\subsection{Thematic Coding}

All transcriptions were reviewed to check for any errors, and printed out, and colorcoded based on both pre-selected categories and also, new emergent themes in order for it to be organized. Thematic coding is a widely used method that is used for qualitative research and basically involves the ways in which researchers manage the data they collect in their interviews, transcribe them, and organize and categorize them into different themes (Neuman, 2011). An extensive time is put towards immersion with the data, so that the researcher understands, and is familiar with the text that has been developed, and the process of coding is developed fully. Codes refer to any semantic feature of data that is salient to the research and appears frequently throughout the transcripts (Neuman, 2011). 
Once I analyzed and coded my data, it was sorted into themes relevant to the intergenerational solidarity framework (functional, normative, and consensual). Themes were established from the data based on the frequency with which participants mentioned them. For example, the word respect was used by the participants several times and would fall under the theme of consensual solidarity because it pertains to values central to the family. By using this method, I was able to outline common themes that were frequently noted in the responses of the respondents, and separated them into specific sections.

\subsection{Limitations to the Study}

An inherent limitation is the time it took to complete this research study. The process of data collection, ethics approval and data analysis took approximately three months. These three months were allocated towards the time it took to have the Research Ethics Board approve of the study which had limited the amount of time to recruit participants, conduct interviews and conduct data analysis.

The size of the sample is another limitation, as the results are not generalizable given that the participants are only a small segment of the Filipino population in Toronto. Another limitation in this study is that throughout the interviews, there was possibility that some of the youths may feel a strong filial obligation and consequently describe their relationship with their parents in a positive light out of fear of shaming the family (see also Tyyskä, 2003). However, I felt that they made an attempt to cover a balance of both negative and positive features. 


\section{Chapter 4. FINDINGS}

\subsection{Impact of Immigration on the Family}

The results reported in this section of the paper suggest that the immigration and settlement processes did have some impacts on Filipino youths and their families. Most participants mentioned that adapting to the Canadian life was an adjustment, as they had to get accustomed to the weather, and because conversing in English was a challenge. Additionally, one individual mentioned that she experienced culture shock due to differing value-systems, while another mentioned cultural differences.

Regarding family relations, many of my study participants responded that their family as a whole grew stronger when immigrating here in Canada, compared to their life back in the Philippines. However, one female participant stated that her relationship with her parents grew more distant, as they became stricter in some respects, such as in school and related to curfews. She states:

They became more strict to me...I don't know. They won't allow me to go out, like in the Philippines. When it comes to studies, they always tell me to put studies first, they became more strict to me, and my brothers. But they allow me to work. But they trust me more back then, not now. They know my friends back then, but now, they know some of my friends.

All of the participants had left the Philippines during their teenage years, so typically leaving behind friends and family can be quite disheartening and depressing.

For one 19-year-old young male, named Ryan when asked about the impact of immigration, he said that: 
Well, living here in Canada is well..is way different. In the Philippines, I had like so much friends...well. like I had lots of friends. All the friends I had speak the same language. In here, I just had to get used to speaking in the Philippines.... And like, the cultural differences are way different.

Ryan goes on to elaborate by saying that:

In terms of the way we talk, the way we relate to others, and like the way we see each other, there's racial differences, back home we're all Filipinos, And like here, well there's some Filipinos, there's some Asians, there's some blacks. But like, other people will discriminate with one another and what not, right.

I later found out that it was not speaking English that was the issue, but conversing in English was, and he also had some insecurity with his accent. However, it is important to note that despite the fact that Filipinos have been exposed to North American culture given the history of American colonization in the Philippines, Filipinos are not acculturated in the 'American life' as the mainstream stereotype would assume (Caliboso, 1998, p. 3). Rather, many Filipinos may struggle to adapt and acculturate because of their inability to converse in English, which has become an issue for many newcomer Filipinos (Caliboso, 1998, p.5). For the majority of the participants, however, the language barrier was not an issue. According to the literature (Caliboso, 1998), economic issues can create problems for Filipino families in such a way that both parents who are employed full time may spend relatively little time with their children. This often results in conflicts around family relationships, communication and discipline of the children (Caliboso, 1998, p. 28-9). However, in the responses from my interviews, almost all of the participants mentioned that their parents in Canada had worked less than they did in the Philippines, and so, family-bonding time was shared more often, 
especially during Saturdays and Sundays. For example, one young female

participant, named Marisa mentioned that in the Philippines, her parents worked overtime every weekday including weekends, and so they hardly had any family bonding time as opposed to here in Canada, where her parents did not have work in the weekends, had the opportunity for family time and was something she cherished and felt happy about. She stated: "Saturday and Sunday is for us. So that's why I love Saturday and Sundays being with my parents and sister".

When asked about the differences between living in the Philippines and in Canada, Marisa, a 21 year old said:

In the Philippines, you have to work to live. In Canada, if you're not working that hard, cause like my mom still works for us, but its lighter, she's sitting pretty in her office right now doing like stuff. Even she is an insurance company, but she told me right now that her work right now is different from the Philippines. in the Philippine she was a manager, and my dad was an IT security officer, and now here right now, he is in inventory sector for a computer company, and for him, it's getting light right now, but he's getting older. But for my mom, she's still pretty sharp, so she works for a insurance company right now. Right now their office is being bought by another company, so right now, her work is light.

In a study conducted by Tyyskä (2006), regarding Tamil families in Toronto, she revealed that Tamils expressed a high degree of family resiliency in the process of immigration and settlement, such as the pooling of financial resources and division of household work. She points out that these youth were aware of the various stresses and adjustments that are associated with the immigration and settlement process, and as such, these youth had appreciated the ways family members work together in order to make things work. 
One of the male participants, named George reaffirms this statement when I asked regarding the differences in their relationship with his parents. He stated: "It didn't change. It even grew stronger, cause when we came here, we had to start all over again, so we had to help each other, we had to understand each other."

This statement seems to indicate that families in the midst of transition of immigrating to a new country develop a mutual understanding with one another aware of the fact that they have to work together and are a source of social support.

This may also indicate that the youths in the study were aware of their parents' "parental sacrifice" for their children's better future in the new country. Although I did not ask about their parents' previous occupation in the Philippines, two participants, Robert and Marisa revealed to me that their parents had relatively good jobs (in clerical, or managerial sector).In fact, Robert's family had a house maid, and they lived in a relatively middle-class neighborhood. At the same time, however, both participants felt that adjustment with respect to a change in their socioeconomic status was not much of a hindrance in their family life here in Canada, rather, a positive outcome in terms of having spend more time together in the weekends has resulted in more family bonding among family members since immigrating here in Canada.

One male participant, Ryan mentioned that they would take advantage of the opportunities afforded to them in the new country, seeing that his parents worked hard to come to Canada for the sake of his future was an important reminder that school was important to him and his parents, and at the same time, it was a duty for 
him to accomplish it in order to fulfill his parents' expectations. Similarly, in a previous study on Iranian immigrant teens in Toronto, Tyyskä (2003) indicates that most of the youths' views about their family relationships had to do with how their parents expect more from them in Canada because there is a wider range of opportunities in the new country. This often leads to pressures on children to do well, and expectations in school and work, which reinforces strong parental involvement in investing on their children, such as financially supporting them in their education and providing the resources the children need.

\subsection{Functional Solidarity}

Functional solidarity refers to general practical support by parents toward teens and vice versa. This can include money issues, housework, giving and getting advice, parents' help with schoolwork and activities (financial, emotional support). In terms of emotional support, one of the participants, Ryan stated:

I only go to my mom for emotional support. Cause I don't really talk to my dad a lot about emotional stuff. I feel weird because...when I talk to someone... like I feel like my dad was a complete stranger, but we're getting closer. So yea, I'm used to talking stuff like that to my mom.

Ryan later told me that his dad had immigrated to Canada earlier than he and his mother did. It was only after his dad had sponsored them, that they began to reconnect. Therefore, that time spent apart from one another was a critical time period, in which he had established a strong bond with his mother, and when coming to Canada he felt slightly awkward and distant from his father. However, throughout his discussion with me, it appeared that his relationship with his father 
has become more of a moral support to him, as his father imparts encouraging words of wisdom and teaches him lessons. He stated:

It's not as close as before. Well, maybe I'm not just...I don't know, cause before I was a kid, so my dad was just spoiling me, so now, maybe my dad is just teaching me what life and what life about, you gotta be strong.

In terms of emotional support, one female individual stated that her parents do provide her emotional support:

Well sometimes yea...,but sometimes no. cause sometimes they're torturing me. cause sometimes they're pressuring me to get a job, but pretty much helping me to bringing me content and happy.....Cause like I seldom cry, But when I was in high school and elementary I always go to them, telling them my problems in school, like being bullied. That's it.

As Herrera (1997) asserts, the attitude of sharing (such as time and money)

is prevalent among Filipino families, whether it be older siblings providing financial assistance to their younger siblings, or often parents sending money back home in the Philippines to their relatives. In fact, one of the participants, the 21-year-old Marisa indicates that she does have more expectations given by her parents than her sibling, because she is the oldest:

Well, yea, cause right now I'm in the working stage right now, so they have different expectation for me. so as I work I should pay umm...their groceries, or electric bills. Unlike my sister, to finish school.

On the other hand, a male participant had mixed feelings about his support from his parents. He mentioned that his parents do provide moral support, such as teaching him to become independent, but at the same time, he felt forced into getting a job. He stated: "They teach me to become independent. They don't force me, but I feel like they forcing me to get a job. It gives me a sense of maturity in life". 
Herein, the young male may feel that his responsibilities and expectations from his parents and to himself may be a bit overwhelming, but certainly, he accepts these expectations, because as he shared with me, by being independent, would benefit himself in the future and also would make his parents proud.

In this particular study, all of the respondents were asked a series of questions regarding the topic of mutual support with one another. Many of the respondents had access to parental financial support given that most of these young people lived with their parents, but some had also indicated that they did have jobs and had an allowance given by their parents. Regarding support by parents in educational choices, most of the youth participants said that they did receive supportive advice by their parents in their decisions for either school, or career, for example, one of the respondents mentioned that: "Oh, yea, for career advice, my parents like help me choosing courses in university, like what course do I apply for in university".

In addressing the importance of support by family members is important to note that mothers and fathers may also give different types of support. For example, one of the male participants, Ryan mentioned:

Yea, especially with my dad. Even through I'm not close with my dad, my dad is still supportive of me especially with my career... What really, I don't want how to describe it...my dad really support me with my career. Like, I want to be a pharmacist, he really teaches me stuff, like math, coz he's good in math, and so that really helps me a lot. And he also encourages me to medical career, coz it's really in demand, because it's going to be demand forever because. And my mom does it as well. she's the type of mother, doesn't really teach about school stuff, she's the one who really pushes you to do your work, to do what you got to do...like be independent and stuff like that. Cause life is going to be always gonna be hard and what not. She always tell me that, whenever they're gone, no one's going to support me, cause l'm the only child so I gotta be independent, I gotta learn to be independent. 
The extent to which expectations were similar or different between parents was important and relevant to understanding how parents may be viewed differently based on the child's perspective, When asked about the differences in parents' expectation, another participant, Marisa stated:

Well actually they compliment. But my dad is more lenient with the expectation unlike my mom she really wants me to finish the degree already and I told my mom I can't handle it, but she's like you have to finish it you have to finish it. But my dad is more lenient.

The support by their parents is the main focus of my paper, but it is also important to note that the support given by the child to their parents is also important in sustaining that mutual intergenerational solidarity of supporting one another as a family. Generally, the comments made when my participants discussed family life was that teens were supportive of their parents as well, for example, in terms of financial support. A couple of the youths mentioned that having a job and helping their family in paying bills were seen as a form of support and also a sense of obligation to their parents. However, they acknowledge an imbalance in that they get more support from their parents than vice versa.

\subsection{Normative Solidarity: (Expectations from Family)}

Normative solidarity basically entails what parents expect from teens and vice versa as members of the family, including areas of disagreement and agreement. Generally teens expect a balance of support, parental involvement, and personal freedoms from their parents. At the same time, it includes youth's views of their responsibility and obligation to perform their filial roles toward their parents. When was asked what they expect from their parents, Ryan stated: 
I expect my parents to be always supportive to me. In all terms, financially, emotionally, spiritually, and like in studies as well, like they can teach me with study techniques, like my dad can teach me with stuff I don't really don't know.

Another question related to the expectations of young adults to their parents, was "What role do you think parents play in bringing up their children"? A young male participant responded:

Communication is the most important thing, even if you're busy, you always have to communicate your child, and you always have to make sure they're going the right way. Some child when they feel like they're not...ummm they feel like their parents don't love them, they start doing some stupid things, like rebellion, you know that.

Similarly, one 19-year-old respondent, Robert, stated:

I think the roles they play is...they umm, want you to be umm a citizen. And like, continue to develop the Filipino values, like respecting parents, respecting the elderly. My parents also want you to succeed in the future, rather than be unsuccessful and live without money.

Interestingly, in most cases, the youths felt that their expectations and feelings toward their parents were generally about what parents wanted for them in terms of being successful in school, and upholding the same values such as respect, and having strong communication with each other. Such values that these youths mentioned are felt so strongly by them and are consistent with the fact that cultural belief systems emphasizing education, personal effort, a sense of responsibility and obligation towards family have been identified to have a positive impact on children, leading to greater academic achievement (Fuligini 1997,cited in Pundir 2009). In a study by Fuligni (1997) participating teens comprised of tenth, sixth and eighth grade students in two high schools and two middle schools in California, comprising of 1,100 students from Latino, East Asian, Filipino and European background. The 
study showed that adolescents from immigrant families - despite coming from families where English was not the primary language they spoke and parents had limited exposure to the education system- were coping well in academics. A strong correlation for explaining this, was the emphasis on education that was shared by students and peers and supported by their parents (p. 8)

In the realm of how the youths felt about the expectations held by parents from their children, it was often about pressure in doing well in school. One male participant, named George shared his feelings about these expectations:

Yea, sometimes, I get pressured. Their expectations are too heavy. Like.... like they expect too much. Like they're not contented if I only do this they want me to be this, sometimes. Like in school, they want me to get a 90 something, if l'm only getting a 75. They want me to be good.

As he mentioned, these expectations in school make him feel pressured, and so when these topics would come up, it would sometimes lead to conflict in the family. But he reassured me later that this is not on a daily basis, and only occurs once in awhile.

When asked the question, "In your opinion, what do you think your parents would say are the most important things they want you to be/do"? Another young female participant, Sara responded: Well, they want me to be a good person, in my own way, they expect me to do well in my studies. They are important to me, 'cause it's the best for me.

I asked: "Do you agree with these expectations?" and she replied:

I agree, because you know some parents, like western parents, they just let their kids do whatever they want, and they end up not that good, their studies are not well, so yea I agree. 


\subsubsection{Sense of Freedom?}

The youths' comments regarding freedoms indicate that parental power over their children is accepted among Filipino youth.

As one young male individual, Ryan stated:

Cause back home, I would say I was an immature kid. So I felt like I'm not really free to do stuff 'cause they still have to discipline me coz I don't know what the best thing to do for myself in the future. But right now, they're giving me more freedom, 'cause I think they feeling a sense of maturity within me. So I feel more independent now.

Although they may accept it, the youth may not feel as close to their parents, such as not confiding to them for their problems, because the idea of having to share their thoughts and confide with their parents would only complicate things, or make things worse, as it will just result to either a lecture, or disappointment by the parents of their children's actions. Hence, as Wolf (1997) suggests, having parental wishes dominate over the youth's own voices/interests results in internal struggles with the individual and within family relations. In addition, Wolf (1997) also asserts that this is also due to an inability to approach parents for fear of shame or hiya of their actions, and often results in more conflicts between parent and child. Conflict over a child's sense of freedom as, Tyyskä (2005) points out is conflicted with what there parents view the consequences of increased freedom as negative because it results in disrespect for parents and elders and a loss of parental control over children. One of the participants, Elizabeth, revealed that confiding to her parents becomes an issue, because it would often result to either an argument, or a lecture by the parents about what is deemed right or wrong, and therefore, she does not open up with her parents in talking about anything that goes on with her life. 
We don't talk like we're friends. Likes its awkward they talk to us about life. We're not open to each other. I don't know coz sometimes they give lectures it's not connected with what I was talking about earlier. Like for a example, one time I was joking around, and they took it seriously and start giving me lectures about life that I already know, they think I don't know that, but...I'm like old enough to know stuff like that.

In addition, gender differences in how parents treat and what they expect from their children is a factor in understanding the dynamics of intergenerational relationships. Often, it is noted that parents (especially the fathers) are highly protective of their daughters, who are often restricted in the home, and are encouraged to take traditionally female careers, such as nursing. When asked about the differences between their father and mother's expectation from them, one female participant, Elizabeth mentioned that:

Well, my mom supports me. It's just my dad. You know. Like my dad always say you always spend money, so you need a job that needs to get more money. But my mom is okay with me being a teacher. My dad actually supports me, but he knows I can do better.

For one male respondent, Ryan, his relationship with his father is more distant compared to his mother. He states:

My dad is more strict, and my mom is more spoiled, spoiling me more. Like my dad, especially in math, I got a low mark, and my dad got mad. And my mom was okay its just mad. My dad expects more, rather than my mom, not just in school, but in general.

And further:

Umm...Yea my father, like there's a favoritism in our family. Like my dad favorites my sister more, and my mom favorites me more. So my dad expects more from me rather than my sister, and my mom expects more from my sister rather than me. so my dad like, especially now that I don't have a job, and he expects me to get a job and like make money. But my mom says like it's a month left till school and school coming up. And my dad doesn't expect 
more from my sister. But my mom expects more... like she goes out every night so she expects my sister to stay home more often rather than my dad.

\subsection{Consensual Solidarity}

Consensual solidarity essentially means the general values and opinions of parents and teens. In addition, the kinds of values, beliefs and attitudes that is central and reflected in the degree of agreement to both teens and parents. For instance, values such as importance of family and friends and educational and vocational choices. The respondents were most likely to agree with their parents on the value of education, although some had pointed out that they disagreed with their parents about the career path they wanted to take.

\subsubsection{Filipino Values}

Regarding values, the Filipino term amor-proprio can be best described as "pride in one's self image; or a strong face that Filipinos present to society in light in which they wish to be seen by others"(Corrgian 2005, p. 22-3). For many Filipinos, having a strong family bond is important and the concern for the family unit comes before an individual's own goals and self-identity. Thus, as Corrigan (2005) asserts, "Filipinos strive to avoid hiya or shame. Many individuals try to avoid inappropriate behavior because of the shame it would bring upon them and their family" (p. 22).

When asked to identify Filipino values, there was a myriad of responses of what it meant. Since it was an open-ended question, I wanted to know their own views of what it meant and explore how it related to family dynamics. One participant (a young male) said that family was at the core of Filipino values. He 
stated: "We like being close together, that's like our value. And like, yea I think that's it"

Meanwhile, another participant, a young male responded quite differently. He stated: "Like saying po", and respect the elders. Probably, partying with family and friends, like family gatherings, like birthdays and stuff. I think high expectations in education, and yea".

Following these questions, a subsequent question was asked if they agreed with their parents' values (regarding anything from traditional Filipino values, or expectations), one young male stated:

I agree. Values like not letting me out for some reason or like rules or what not. As I've said earlier, they just want the best for me, what they're doing and what doing now, they all did that for my sake.

This is consistent with the findings by Xiong and colleagues (2005) who cite that based on some scholars (LeVine 1988 cited in Xiong et al., 2005, p. 160), despite years of living in the country of resettlement, family values, such as household chores, family obligations and family roles remain intact or stable. Traditionally, children are encouraged to be dependent on the parents and are taught to be respectful and obedient to authority, particularly to parents and elders.

The topic of 'Being Filipino' and knowing what Filipino values mean to them highlights the importance of understanding about how these youths interpret and negotiate their ways of being a Filipino and living out these values set out by the family and cultural traditions. That said, it sheds light to whether or not there are

\footnotetext{
1 "po" is a Tagalog word to use respect to elders.
} 
agreements or disagreements between parent and child. One female participant, Marisa shared her thoughts about what Filipino values mean to her:

Values are like being respectful. And being loyalty and god-fearing. And then, being helpful to one another, if there's problem, there help you no matter what happen. And lastly, they're being...there's a certain value, bayanihan ...which means like helping each other, if one person has a problem, the whole barangay will help you...that's what I love of Filipinos.

Such sentiments of what Filipino values mean to her, have similar but varied responses. Sara points out that for her, being strict in education, showing respect to elders and being family-oriented are key aspects of what she believes are Filipino values:

Typical Filipino values...umm...like cause you know Filipinos are really strict about their studies and being respectful to elders. Like, family comes first, 'cause I need their approval, especially for my parents.

Having been prompted by: "But in terms of career, it is different?", she said: "Yea its different. 'Cause I don't know... they feel that if I do something I don't wanna do, I want be successful,. So they want me to do what I want". I followed up with: "So they give you freedom?" she added: "Yea, but in terms of family values...no".

Based on these statements, it seems that when it comes to education, and career, there is an extent of freedom in their choices of what they would like to pursue. Marisa mentioned that she views her parents as her career advisors, but at the same time, feels that she needs the freedom that she must have in order to make her own decisions, which she does feel that her parents do offer to her:

Well, like, when I decided to take hotel management rather than culinary arts, we have conflicts there. So education. But after they let me be. So right now, after this, like right now they're my career advisors, right now, I have a hard time in the industry I taken, so they're giving me advice. 


\subsubsection{Filial responsibility and expectations}

When asked questions surrounding expectations by their parents, some of the participants mentioned the word "responsibility" or "being responsible" to describe how their parents expectations were to them, and also, how they felt they were expected to be. Sara said: "They expect me to be responsible, respectful to other people. They expect me to still have the manners of Filipino, like you know mano". I later asked her what did she think about these expectations from her. She responded: "I feel sometimes pressured, cause they're telling me to do that. But yea, I feel obligated, because I want to be responsible too".

Based on Sara's response, there is a sense in which filial responsibility is deemed important for this young individual. Ensuring her parents' approval by following their expectations, in this case, family values of respect, are generally typical for most parent-child relationships.

I later asked a male participant, Robert about how he felt about the expectations from his parents, and he told me:

Like when I'm angry I feel that. Cause sometimes I get mad to my parents. Because my parents don't let me go out for some reasons. And, yea so I get mad at them, but then I realize they really have a point of not going out and studying I realize it's the best thing for me. Cause my parents really want the best thing for me right So I try to respect their decisions, so I kinda try to move along with want they only want. I'm the only child they want me to be successful. So they really want the best for me...not to me...I don't know.

For Robert, there is a strong sense of filial responsibility. His obedience to his parents' wants and desires for him is accepted, as he states the just wants to "move along with what they only want". This particular statement seems to suggest that his own interests are suppressed for the sake of his parents' approval. This can prove to 
be challenging for youth who may want to question or take autonomy for their own decisions and choices in life.

A similar response came from a female participant, Marisa:

For me, I know that I'm pressured but I'm kina used to it. I'm just like, I know my goals, I don't care what my parents say, cause I know my goals and I told these things to them, so I just need their guidance from them, and just let me be. I'm not pressured anymore, cause I know my goals already and they know my goals already.

I later asked her to elaborate on how she felt about those expectations. Marisa responded:

For me its pressured. 'Cause I know my strengths and expectations, but my mom is like pushing me to the limit already to finish the degree, that's why I was like...I don't want to take much roe that I cannot do. Cause like I know my limitations already, like for me I get easily tired, I can do it, but don't pressured me, but let me know it on my own please, that's what I want. but my mom is like do it do it.. it's for your own good, that's why I was like... like I don't want this pressure anymore. That's why I feel pressured this time.

The literature on filial responsibility and family obligation seems to hold true for these youth who remain highly involved with their family affairs, as they maintain strong ties with their parents. Fuligini and Pederson (2002) would describe this as a form of family obligation, which refers: to "...[t]he extent to which family members feel a sense of duty to assist one another and to take into account the needs and wishes of the family when making decisions" (p. 856).

Ryan stated:

Yea I feel that a lot of times. Like I'm the only child, they expect me to support them in the future. So yea, all the things l'm doing, it's important to me and to my parents to make them happy.

These ties are linked to their sense of duty and in some ways, to their appreciation for what their parents had sacrificed for them in order to achieve a 
better future for their children and for the rest of the family. Filipina scholar Medina (1991) asserts that:

There is a very strong filial bond between parents and children, as parents are loving, caring and protective. They train and discipline their children very early in life with high hopes for their bright future. They aspire to have their children attain a high level of education. In return, children love, respect, and obey their parents (p.16).

Such a statement is highly indicative of what seems to be occurring among these youths who feel obligated to their parents, and even more so, to their family and upholding the same values, and expectations, in particular, as the youths have pointed out, the high expectation on education.

\subsection{Additional Aspects of Intergenerational Relations}

\subsubsection{Relationship with Parents}

An important component in intergenerational solidarity is to understand the detailed dynamics of the youths' relationship with their parents. One female participant, Sara responded:

Yea, but like I said, with my dad we don't talk as much cause he's really busy, but my mom we do talk. Like what happen today, at work, what I ate, just general stuff. With dating, it's my mom. With my sister, mom and me we like to go shopping every weekend, going to the church, like every weekend.

For the most part, the participants had described their relationship with their parents as relatively good. The majority of them believed that their family as a whole grew stronger after immigrating into Canada, and as a result, a stronger bond was formed between each other. Interestingly, when I asked how is their relationship with their parents, many of them said it was generally good, very close, 
but at the same time, there were differences in who they bonded with more, in terms of mother and father. For instance, Sara states:

Yea, 'cause back in the Philippines I wasn't really close to my mum, I was close to my dad. But when I came here, it was totally opposite, I don't talk to my dad cause he always working, and like my mom she's always with me. Sometimes it kind of sucks, coz umm we're really close like my dad, we used to be really close but now, it's just not that close.

As indicated in the above statement, the relationship changed for Sara, as she mentioned to me that her mother had immigrated before them and later sponsored the rest of the family members, including herself, her sister and father, a few years later. In addition, the amount of time spent with one another was limited because all of her family members, including herself was working. Hence, such issues were reasons why her relationship with her parents had changed, which includes the quantity and quality of time spent with one another.

\subsubsection{Education}

Throughout the interview, I asked the participants questions about their expectations from one another, and the majority of them mentioned that the educational aspect of doing well in school and getting high grades was important. The Filipino attitude on placing a high value on education has been carried on to Canada by immigrants (Aranas, 1983,p.128). There is often an immediate concern among Filipino parents to look after the education of children.

When asked about the differences about parenting styles between Westernized and Asian (Filipino) parents, Ryan stated,

For Asian Filipino parents, basically, the main point is, Asian parents are more strict than westernized parents. Not to be general, but Asian parents are more strict in education, especially. Cause like, whenever I go home, you gotta study, get out your books. For westernized parents, I'm not sure 'cause 
haven't experience, but like how westernize people act, not really strict to them.

Thus, education by Filipino parents is strongly emphasized and encouraged.

In doing so, Filipino youth often put a lot of pressure on themselves to do well in school, by being serious about their studies, and keeping in mind that failure to meet expectations would be shameful or embarrassing for both the child and the parent (Corrigan, 2005, p. 22).

One young female participant stated that her desire to become a teacher rather than a nurse was one of the issues where her choices conflicted with her parents' expectations. Elizabeth stated:

Okay, for Filipinos, I don't know they want their kids to be respectful, like mano ${ }^{2}$. They're more strict, I don't know. They're more...they want their kids, they expect kids to get higher marks in school. My parents want high grades, they expect me to be a nurse, but I don't really want to. I want to be a teacher for kids, but they expect more from me. Like they want me to become a nurse, but I told them I don't want because I won't be happy if I become a nurse. They say their okay, deep inside, 'cause.. like they want me to...'cause they know I can do better, but I don't want to.

According to Wolf's (1997) study of several Filipino university students in California, regarding family pressures and obligations, the pattern of pushing their children to do well in school or follow a major that will lead to a "safe" possession was not unusual among Asian immigrant parents. Often many parents have high aspirations for their children's academic careers (Scalibini et al., 2006, p. 91), especially immigrant parents, which can often create family conflict or tensions around parents and their children as indicated in her study. This is because the

\footnotetext{
${ }^{2}$ The Filipino tradition to reach one's right hand to an elder's hand and put it towards an elder's hand and put it towards one's forehand as an act respect or greeting.
} 
youth may feel that their lack of freedom to choose their own educational or professional paths limits their ability to be more independent, and instead they are tied to what their parents want from them. However, in my study, many of the participants had expressed a mutual understanding with each other about what they wanted to take as a career path, and although parents had certain careers they preferred for their children (such as doctors, or lawyers) for example, as one participant shared with me, that once he expressed a strong desire for a particular career, their parents accepted it. This is consistent with Shariff's (2006) study on South Asian parents where they often believe it is their social and moral duty to foster educational achievement in their children, and if their children desire a lower status profession, conflicts often arise.

\subsubsection{Strong Family}

The question of what is a strong family is inherently relevant to my theme on intergenerational solidarity. One of the female participants, Marisa, stated:

A strong family to me, is respecting one another is important. And trusting one another, and trustful to one another. Love, strong faith, loving one another and praying for each another. Let's say, for like... for a strong family, if there's a problem you should help one another, not just oh I don't care with you just go on your own. It's supposed to be intact for better and worse. It's supposed to be a partnership between the individuals in that unit .because a family wont work, if each individual has their own life. That's a strong family for me.

Similarly, Robert said:

I think family is about supporting each other. Being there at all times. And like,... Not giving up, even though a bad thing happen to them. Just being supportive for whatever reasons. 
Based on these two responses, the family and their perspective on a strong family are very much important to these youths. Various terms, such as "being supportive", "always there for you through ups and downs", are some of the examples that were brought up throughout my discussion with these youths. It is important to note that mutual respect and understanding are key aspects of intergenerational solidarity, and although there may be some disagreements or conflicts, for instance around dating, and career choices. It was evident that the general feeling that these youths had about their families and their expectations of what is a strong family are important to them. Moreover, I found that their views about their families, and in particular their relationship with their parents have been relatively positive. This may partially be due to their age. As they are transitioning to young adults, they may feel that they are at a period of their lives, where they still are dependent upon their parents, but at the same time, they seek independence and freedom. Therefore, mixed feelings and emotions may arise, which may lead to some conflicts or disagreements. Another factor could be that being relatively new immigrants, they understand what their parents are going through. As the literature suggests, families serve as a social support system, especially in cases of immigrating to a new country. In such cases, they understand their responsibilities, their obligations as well as expectations from their parents and themselves. 


\section{Chapter 5. DISCUSSION}

In general, my findings have been best explained through the intergenerational solidarity framework, as developed by American researcher Vern Bengston. Built on the three chosen dimensions of normative, functional, and consensual, the intergenerational solidarity model highlights the various aspects of family solidarity.

Based on the findings in this study, it seems that the majority of the youths adopted a bidirectional acculturation experience, by seeking to adopt the mainstream culture, while at the same time, manifested a desire to maintain ties with their culture of origin. For example, most youths saw themselves as being Canadianized, after living in Canada for a few years, and socializing with Canadians as well attending school. They also, however, felt strong Filipino values attached to them. Meanwhile, regarding on the impact of immigration, there was a sense in which the youth were aware and had expected the changes that would happen in terms of overall culture and lifestyle when immigrating to Canada. For example, a couple of the participants mentioned that they were told by their parents life would be different once they arrived to Canada, and since immigrating, assisting the family by trying to get a job, or helping out with extra chores was ways of demonstrating their support to their family in times of need. In regards to family relations, most participants felt that their relationship with their parents actually grew closer, since they were aware that things would be different upon immigrating in Canada (such as their lifestyle), exemplified by the case of the family that had experienced 
downward social mobility but was seen by the respondent to have grown closer upon immigration.

With respect to consensual solidarity, the clash between different attitudes and opinions seems to be more applicable in certain areas, such as dating and curfews, rather than differing value-systems such as cultural or family values. For normative solidarity, I found that expectations and obligations in family matters, such as school and the youth participants deemed career aspirations important. However, conflicts of interests often arose between the youths' interests over their parents' interests, for example, in the realm of deciding their future career paths, which resulted into some minor disagreements. In regards to functional solidarity, receiving general practical support by their parents in the realm of emotional and financial support was provided to them, especially in the educational front, and providing assistance in schoolwork. However, emotional support was not the case. A few of the male participants mentioned that they did not confide to their parents for emotional support, because it was a sign of weakness to them, while a couple of female participants, had said they did not feel comfortable, or did not want to give additional stress to their parents by sharing their problems to their parents.

While general positive remarks were made about relationships with parents, it is important to note, that there were a few differences in how the youth thought of these relationships. As I noted before, most had positive feelings, commenting that their family grew closer together, but a couple also mentioned that they grew more distant, especially with one of their parents - either their father or mother. In both cases, it was because one of the parents had immigrated earlier than the rest of the 
family, and the distance apart led to emotional and physical detachment. However, despite of some initial rifts after family reunification, the display of maintaining strong kin ties via family sponsorship can highlight the significant role it plays for Filipinos in the assistance of the immigration process. Nevertheless, most of the participants believed that they actually had more time together to bond, compared to their life back in the Philippines. This suggests that these participants generally felt that their relationship with their parents improved in some aspects.

Overall, based on the youths' responses, there seems to be a hierarchical relationship but also, a mutual understanding between parent and child. This can be due to the influence of strong filial values, and sense of obligation, but can also be explained by the youths' current place in the family, as their sense of dependency and need for parental support remain high. For instance, the youth mentioned to me that they still felt they had to meet their parents' expectations and get their approval, especially in certain areas such as performing well in school, and choosing their parents' educational/career choices, which sometimes resulted to disputes. Yet, when it came to going along with family values/traditions, and showing respect for elders (showing 'mano' to elders) - they were mutually agreed upon - and this may be due to the youths' awareness of the parental sacrifice for their children. Another possible explanation would be the developmental stake, in which the young adolescents may want to perceive large differences in certain attitudes and beliefs, or seek for their own independence and autonomy in order to develop their own identity. Yet, the dependency on parental support is still heavily relied upon by the youths and may explain why their sense of obligation to their parents is strong. 
Generally, such expressed mutual understanding with their parents, coincides with their general feeling of gratitude, and of filial obligation, in which the youths felt 'indebted' to their parents for what their parents have provided for them. The level of closeness between youth and their parents may differ, and indeed issues around dating, educational choices and degree of freedoms may also be sensitive pressure points, but nevertheless, as the youths' indicate, their parents gradually accepted and allowed them more freedom to make their own decisions.

\subsection{Implications and Future Research}

There are implications for social service delivery practices based on this study. Given the steady rise of immigration, it has significant implications for educators, service delivery providers and governments to improve family support programs as a way to ease immigrant families, specifically, immigrant youths in the integration process in Canada. For example, providing after-school programs for youths (to help integrate and socialize them into mainstream society), as well as employment assistance programs for parents, all must be culturally and ethnically sensitive to their specific needs. Therefore, providing needed attention towards immigrant youth is essential in many socio-economic respects.

Also, this study can help social workers assist with some issues that Filipino youths may face in their families (such as, cultural matters) which can affect their performance at school, at home, or their integration. It is also important for social workers to gain knowledge about the Filipino culture. Given that Filipinos are a diverse culture, it is essential as Caliboso (1998) writes, "...[f]or social workers to become knowledgeable of how the acculturation process impacts the individual as 
well as family functioning" (p. 68). Caliboso (1998) further adds, that having knowledge of acculturation is important for appropriate assessment and effective intervention with Filipino individuals and families (Caliboso, 1998, p. 68-9). Thus, future research is needed about how acculturation impacts the family dynamics Filipinos living in Canada.

Overall, this study fills the gap in the literature by gaining insight into the dynamics within Filipino parent-child relationships based on the youths' perspective. The subjective perceptions of the youth are an essential component in understanding the life course of a parent- child relationship. Using aspects of the solidarity model can help provide the basis for understanding the change and continuity in families in the process of integration. With regards to academia, this research paper offers insight to the Filipinos as an ethnic group that has been relatively understudied in Canada. It also sheds new light on family relations in the immigration and settlement process.

As mentioned earlier, given that the greatest limitation in this paper is its sample size, future research should include a much larger, more diverse and representative sample. Also, it may be useful to conduct a comparative study involving youth of different ages and backgrounds (divorced parents, singleparents), second-generation youths, adult children, and include other members of the family, such as parents, grandparents, and siblings. By doing so, one will further gain insight into the complexities of intergenerational relationships from different subjective perspectives of family members. 
Another area for future research would be exploring the dimensions of the solidarity model not examined in this paper (affectual, associational, and structural) in order to better gain insight about how families fit along the continuum of harmony and conflict between family generations. Indeed, while this theory has been useful in explaining family solidarity, further research should examine how concepts of family resiliency and intergenerational ambivalence can further the discussion on the nature of family ties. 


\section{Appendix 1}

Interview Guide:

Interviews will be open-ended and semi-structured. In order to capture similarities and differences in youths' relationships with their parents, questions will be asked in relation to both parents.

Opening

I just want to remind you that all the information you give will be kept confidential and you can choose not to answer any questions you may feel uncomfortable answering.

You will be asked a number of questions about your relationship with your parents. In each question, think of whether there are similarities and/or differences between your parents, with regard to their relationship and expectations from you.

General questions

1) Where were you were born and when did you come to Canada?

2) Who are your family and what are your living arrangements (i.e. live with father/mother/ both)?

3) How do you feel about your family?

Impact of immigration

4) Do you find any differences in living here in Canada versus the Philippines?

Prompt: (if not/yes) Why do you think that it is the case?

5) In your opinion, has your relationships with your parents changed since coming here to Canada?

Prompt: Become more closer or more distant?

6) In your opinion, what are the differences in parenting styles between

Westernized vs. Filipino (Asian) Parents?

Prompt: If no differences, Why?

Prompt: If yes, do you think your parents have adopted a more western parenting style? How?

7)What role do you think parents play in bringing up their children?

8) What is most important when bringing up children?

9) What does a family mean to you?

Prompt: What is a strong family? How should family members treat one another?

Relationships with parents

10) How do you describe your relationship with your parents?

Prompt: Is it generally good or bad?

Prompt: Do you talk with your parents often?

Prompt: What about?

11) What are some of the things that you and your parents enjoy doing together as a family?

12) How often do you spend time with one another?

General Practical Support (Functional Solidarity)

13) Do your parents offer their help to you?

Prompts: in homework, school, career advice?

14) Do you often go to your parents for emotional support? 
15) Do your parents provide financial support

Prompts: paying for school, allowance?

Family Values (Normative Solidarity): Expectations from one another

16) What are your parents' expectations from you, as a member of your family?

Prompt: How did they discipline you?

Prompt: Were Are there any rules in the house?

Prompt: Do you agree with some of their expectations (i.e., education, housework)? Why, or why not?

17) Do you find there are differences between your parents (mother/father) about what they expect from you?

Prompt: How do you feel about these expectations (e.g., feel obligated, or pressured)?

18) Is your parents' approval important to you?

19) What are your expectations of your parents?

Prompts: be more flexible, understanding (or respect), be more like "other parents [Westernized]?

20) Do you find that your parents treat you differently and expect different things from you compared to your other siblings or as a son/daughter/only child?

General Values "Being Filipino" [Filipino Values] (Consensual Solidarity]

21) What would you say are typical Filipino values?

22) In your opinion, what do you think your parents would say are the most important things they want you to be/do?

Prompts: in terms of family, friends, career plans?

Prompt: Are these important to you? Why or why not?

Prompt: Do you agree with your parents about their values? Why or why not?

23) Being part of this religious group, how important is religion to you? How important is it to your family? 


\section{References}

Anisef, P., and Murphy Kilbride, K. 2002. The Needs of Newcomer Youth and Emerging "Best Practices" to Meet Those Needs. Toronto: CERIS.

Aranas, Marcial Q. 1983.The Dynamics of Filipino Immigrants in Canada. Edmonton: Coles.

Bales, Stephanie Stigler. 2002. The Relation Between the Grandparent-Grandchild Bond and Children's Views of Themselves and Grandparents. Indiana: Indiana University.

Bengston, Vern, Roseann Giarrusso, J. Geth Mabry, Merril Silverstein. 2002. Solidarity, Conflict, and Ambivalence; complementary or Competing Perspectives on Intergenerational Relationships? Journal of Marriage and Family. 64: 568-576.

Bengston, Vern, and Merril Silverstein.1997. Intergenerational Solidarity and the Structure of Adult Child-Parent Relationships in American Families. AJS. Vol $103(2): 429-60$.

Bengston, Vern and Roberts. 1991. Intergenerational solidarity in aging families: An example of forma theory construction. Journal of Marriage and Family. 53: 856-870.

Betsayda, Mary Grace T. 2008. Bahala na ang Dios": The Church's Role in the socialization of Filipinos in The Greater Toronto Area. Toronto: Ryerson University.

Caliboso, Sarah, Librando. 1998. Acculturation and family functioning among immigrant Filipino families. Long Beach: California State University.

Caro, Josie Fely. 2008. The Educational Experiences of Filipino youth in Quebec in the context of global migration. Montreal: McGill University.

Chao, Ruth, K., and Kevin F. Kaeochinda. 2010. Parental Sacrifice and Acceptance as Distinct Dimensions of Parental Support Among Chinese and Filipino American Adolescents. Asian American Parenting and Parent-Adolescent Relationships. 61-77.

Chen, Anita, Beltran. 1990. Studies on Filipinos in Canada: State of the Art. Canadian Ethnic Studies, 22(1):83-95.

Chun, Jong Serl, and Joohee Lee. Intergenerational Solidarity in Korean Immigrant Families. Journal of Intergenerational Relationships. 2 (2): 6-21. 
Cimmarusti, Rocco. 1996. Exploring Aspects of Filipino-American Families. Journal of Marital and Family therapy. 22 (2): 205-217.

Corrigan, Jim. 2004. Filipino immigration. Philadelphia: Mason Crest Publishers.

Costigan, Catherine L., and Daphne P. Dokis. 2006. Relations Between Parent-Child Acculturation Differences and Adjustment Within Immigrant Chinese Families. Child Development. 77(5):1252-1267.

Cruz-Saco, Maria Amparo, and Sergei Zelenev. 2010. Intergenerational Solidarity: Strengthening Economic and Social Ties. New York: Palgrave Macmillan.

Dinh, Khanh T, and Huong H. Nguyen. 2006. The effects of acculturative variables on Asian American parent-child relationships. Journal of Social and Personal Relationships. 23(3):407-426.

Espiritu, Yen Le. 2001. "We Don't Sleep Around like White Girls Do": Family, Culture, and Gender in Filipina American Lives". Journal of Women in Culture and Society. 26(2): 415-440.

Fuligni, Andrew J., 1997. "The Academic Achievement of Adolescents from Immigrant Families: The Roles of Family Background, Attitudes, and Behavior", Child Development, 68(2):351-363.

Fuligini, Andrew and Sara Pederson. 2002. Family obligation and the Transition to Young Adulthood. Developmental Psychology. 38(5): 856-868.

Hassan, Ghayda, Cecile Rousseau, Toby Measham and Myrna Lashly. 2008. Caribbean and Filipino Adolescents' and Parents' Perceptions of Parental Authority, Physical Punishment, and Cultural Values and Their Relation to Migratory Characteristics.Canadian Ethnic Studies. 40(2): 71-182.

Hebblethwaite, Shannon. 2008. The family that plays together, stays together? Understanding the experience of intergenerational family leisure. Guelph: University of Guelph.

Herrera, Dana S. Ramos. 1997. Adaptation of the Filipino Family upon immigration to the United States. Lambda Alpha Journal.27: 1-22.

Hindin, Michelle, J. 2005. Family dynamics, gender differences and educational attainment in Filipino adolescents. Journal of Adolescence.28: 299-316.

Hyman, I., Vu, N and Beiser, M. 2000. Post-migration stress among Southeast Asian refugee youth in Canada: A research note. Journal of Comparative family Studies. 281-293. 
Khabagnote, Farrah. 2003. Filipino-Americans and the Pregnant Adolescent: Family Attitudes, Cultural Values and Acculturation. San Francisco Bay: Alliant University.

Li, Winny, Ang Chiu. 2006. Negotiating spaces of belonging: social support in Filipino immigrant youth. Montreal: McGill University.

Lowenstein, Ariela. 2007. Solidarity-Conflict and Ambivalence: Testing Two Conceptual Frameworks and Their Impact on Quality of Life for Older Family Members. The Journals of Gerontology. 62B (2): S100-S107.

Mangen, David J, Vern L. Bengston and Pierre H. Landry Jr. 1988. Measurement of Intergenerational Relations. Newbury Park: Sage Publications, Inc.

Medina, Belen T. G., 1991. The Filipino Family A text with selected readings. University of the Philippines Press. Quezon City:

Merz, Eva-Mari, Hans-Joahim Schulze and Carlo Schuengel. 2010. Consequences of Filial Support for Two Generations: A Narrative and Quantitative Review. Journal of Family Issues, 31(11):1530-1554.

Merz, Eva-Maria, Frans J. Ort ,EzgiOzeke-Kocabas and Carlo Schuengel. 2009. Intergenerational Family Solidarity: Value Differences Between Immigrant Groups and Generations. Journal of Family Psychology. 23(3):291-300.

Monserud, Maria A. 2008. Intergenerational Relationships and Affectual Solidarity Between Grandparents... Journal of Marriage and Family. 71(1):182-195.

Phinney, Jean, S, Anthony Ong and Tanya Madden. 2000. Cultural Values and Intergenerational Value Discrepancies in Immigrant and Non-immigrant Families.Child Development. 71(2): 528-539.

Pundir, Chanda. 2009. Negotiating Cultural Transmission: Asian Indian Immigrant Parents and Children. Toronto: Ryerson University.

Scalibini, Elena, Marta and Margherita Lanz. 2006. The Transition to Adulthood and Family Relations. An Intergenerational Perspective. Sussex: Psychology Press.

Shariff, Aneesa. 2006. Gender, Acculturation, Ethnic Identity, and Parenting Stress Among South Asian Families. Edmonton: University of Alberta.

Stuart, Jaimee, Colleen Ward, Paul E. Jose and Pancha Narayanan. 2010. Working with and for communities: A collaborative study of harmony and conflict in well-functioning, acculturating families. International journal of Intercultural Relations.34:114-126. 
Tyyskä, Vappu and Sandra Colavecchia. 2001. “Report of Individual Parent Interviews in Toronto", Sub-report in Research Project entitled Study of Parenting lssues of Newcomer Families in Ontario. CREHS and CERIS.

Tyyska, Vappu. 2001. Long and Winding Road. Adolescents and Youth in Canada Today. Canadian Scholars Press Inc.; Toronto.

Tyyskä, Vappu. 2003. Solidarity and Conflict: Teen-Parent Relationships in Iranian Immigrant Families in Toronto, in Lynn, Marion, ed. Voices. Essays on Canadian Families. 2nd edition. Toronto: Nelson Canada.

Tyyskä, Vappu. 2006. Teen-Parent Relationships in the Settlement of Sri Lankan Tamils in Toronto, CERIS Research Colloquium, Feb. 10.

Vedder, Paul and Michiel Ootwijin. 2009. Adolescents' Obligations toward their families: Intergenerational Discrepancies and Well-being in Three Ethnic Groups in the Netherlands. Journal of Comparative Family Studies. 40(5):699717.

Weiner, Irving, B, Donald K. Freedheim, Richard M. Lerner, M. Ann Easterbrooks, John A. Schinka, Jayanthi Mistry. 2003. Handbook of Psychology: Developmental psychology. New Jersey: Jon Wiley and Sons.

Wolf, Diane. 2002. "There's no place like home". In Peggy Levitt, The Changing Face of Home: The Transnational Lives of the Second Generation. New York: Russell Sage Foundation. 259-287.

Wolf, Diane. 1997. Family Secrets: Transnational Struggles among Children of Filipino Immigrants. Sociological Perspectives. 40 (3): 457-482.

Wong, Siu Kwong, 1999. "Acculturation, Peer Relations, and Delinquent Behavior of Chinese-Canadian Youth", Adolescence, 34[133):107- 119.

Wu, Chunxia and Ruth K. Chao. 2005. Intergenerational cultural conflicts in norms of parental warmth among Chinese American immigrants. International Journal of Behavioral Development. 29(6): 516-523.

Ying, Yu-Wen, Peter Allen Lee, Jeanne L. Tsai, Yu J. Lee, and Malisa Tsang. 2001. Relationship of Young Adult Chinese Americans with their Parents: Variation by Migratory Status and Cultural Orientation. American Journal of Orthopsychiatry. 71(3): 342-349.

Xiong, ZhaBlong, Patricia A. Eliason and Daniel F. Detzner and Michael J. Cleveland. 2005. Southeast Asian Immigrants' Perceptions of Good Adolescents and Good Parents. The Journal of Psychology. 139(2):159-175. 
Zerat, Semhar. 2009. Identity Retention and Sense of Belonging: An Examination of Second Generation Youth in Toronto: Ryerson University.

Zhou, Min. 1997. Growing Up American: The Challenge Confronting Immigrant Children and Children of Immigrants. Annual Review Sociology.23:63-95.

Zohar, Even, Ahuva Sharlin. 2009. Grandchildhood: adult grandchildren's perception of their role towards their grandparents from an intergenerational perspective. Journal of Comparative Family Studies. 40 (2):167-185. 